\title{
Effectiveness of Laparoscopic Surgery for Gallstones and Common Bile Duct Lithiasis: a Systematic Overview
}

\author{
Efectividad de la Cirugía Laparoscópica para Colecistolitiasis y Coledocolitiasis: \\ Revisión Global de la Evidencia
}

\author{
"Carlos Manterola; "*Viviana Pineda; ${ }^{* * *}$ Montserrat Tort; \\ ${ }^{* * * * *}$ Eduardo Targarona; ${ }^{* * * * *}$ Román Villegas Portero \& ${ }^{* * * * * *}$ Pablo Alonso
}

\begin{abstract}
MANTEROLA, C.; PINEDA, V.; TORT, M.; TARGARONA, E.; VILLEGAS, P. R. \& ALONSO, P. Effectiveness of laparoscopic surgery for gallstones and and common bile duct lithiasis: a systematic overview. Int. J. Morphol., 28(3):729-742, 2010.

SUMMARY: The aim of the present study was to evaluate the available evidence on the effectiveness of laparoscopic surgery for treating gallstones and common bile duct lithiasis (CBDL). A systematic overview was performed. Medline, EMBASE and The Cochrane Library were searched (1998-2008). Systematic reviews (SR), clinical practice guidelines (CPG), randomised clinical trials (RCT) and observational studies were included. Internal validity and overall quality of the evidence were assessed. The available evidence was classified according to the Oxford Centre for Evidence Based Medicine proposal. 87 studies were included in this review (12 SR, 23 RCT, 3 CPG, 13 cohort studies, 3 cross-sectional studies, 2 case and control studies and 31 case series). Compared with open cholecystectomy, laparoscopic cholecystectomy (LC) is associated with shorter operating time, shorter hospital stay and better quality of life (high quality evidence). The use of antibiotic prophylaxis does not appear to reduce the infection rate in low-risk patients (high quality evidence). Although many techniques have been advocated to perform LC their effectiveness is as yet inconclusive (low-quality evidence). Two-stage surgery is the most appropriate strategy for high-risk patients with CBDL (high-quality evidence). Mortality is similar to open surgery, as the effectiveness is similar to that of endoscopic treatment (high-quality evidence). As a conclusion we can state that the evidence concerning the effectiveness of laparoscopic surgery for gallstones and CBDL is scarce and of low methodological quality and that better quality studies are warranted to assess these techniques more adequately.
\end{abstract}

KEY WORDS: Cholecystolithiasis; Choledocholithiasis; Cholelithiasis; Gallstones; Laparoscopy; Cholecystectomy; Laparoscopic; Technology Assessment; Biomedical.

\section{INTRODUCTION}

The use of laparoscopic procedures for treating hepato-biliary diseases started in the late eighties when Mouret, Doubois and Perissat performed the first laparoscopic cholecystectomies (LC) in-patients with cholecystolithiasis (Perissat, 1989; Litynski, 1999; Vecchio, 2000; Reynolds, 2001; Jaffray, 2005). LC quickly became the first-line treatment for uncomplicated cholecystolithiasis (Weil, 1992), promoting research on the application of laparoscopic procedures in various surgical contexts. Many approaches were quickly developed and the field has undergone revolutionary changes (Matthews, 1999; Young-Fadok, 2000). Evidence in favour of LC, however, is scarce. Furthermore, the advantages of laparoscopic techniques do not appear to outweigh those of open approaches yet (Troidl, 1999).

Full Professor, Hepatobiliary Surgery Unit, Department of Surgery, Faculty of Medicine, Universidad de La Frontera, Temuco, Chile.

** Assistant Professor, Mastology Unit, Department of Surgery, Faculty of Medicine, Universidad de La Frontera, Temuco, Chile.

*** Iberoamerican Cochrane Centre, Spain. Epidemiology and Public Health Department, Universidad Autónoma de Barcelona, Hospital de Sant Pau, Barcelona, Spain.

***** Full Professor, Department of Surgery, Hospital de Sant Pau, Universitat Autonoma de Barcelona, Barcelona, Spain.

****** Andalusian Agency for Health Technology Assessment, Sevilla, Spain.

******* Iberoamerican Cochrane Centre, Spain. Epidemiology and Public Health Department, Universidad Autónoma de Barcelona, Hospital de Sant Pau, Barcelona, Spain.

Sources of financial support: Andalusian Agency for Health Technology Assessment and DID-UFRO Project DI09-0060 of the Universidad de La Frontera Research Direction. 
The aim of this study was to systematically review the available evidence on the effectiveness of laparoscopic surgery for treating gallstones and common bile duct lithiasis (CBDL).

\section{MATERIAL AND METHOD}

The following databases were searched: Cochrane Library, Medline and EMBASE. The TRIP Database engine and several international technology assessment agencies were also searched. All studies evaluating the effectiveness of laparoscopic treatment in patients with cholecystolithiasis or CBDL, published between 1988 and 2007 in English, French or Spanish were considered. Firstly, systematic reviews (SR), clinical practice guidelines (CPG) and randomised clinical trials (RCTs) were retrieved. The internal validity of studies was assessed and synthesised in evidence tables (SIGN, 2004). If this type of design was not available observational studies were included. The available evidence was classified according to the system proposed by the Oxford Centre for Evidence Based Medicine (OCEBM, 2006) and the overall quality of the evidence for each intervention was rated as high, moderate or low quality in a modified approach of the GRADE system (Guyatt, 2006). This approach considers not just the study design but other issues like internal validity, consistency, precision of results, and whether evidence assessment was direct or indirect.

We did not formulate recommendations in this report because these are specific to each setting. Besides the overall quality of the evidence and the balance between risks and benefits, recommendations need to take into account local factors, values and preferences, the baseline risk of the population of interest, and costs (Guyatt, 2006).

\section{RESULTS}

1951 records were retrieved and 87 studies meeting the selection criteria were finally included (Fig. I).

\section{Effectiveness of laparoscopic cholecystectomy}

Laparoscopic versus open cholecystectomy. Four SRs (ANDEM, 1994; Downs, 1996; Korolija, 2004; Keus, 2006a; Keus, 2006b), two RCTs (Mimica, 2000; Ros, 2001), three cohort studies (Devereaux, 2005; Elder, 1996; Finan, 2006), one CPG (Zacks, 2002), one cross-sectional study (Collet, 1997) and one case series (Ibrahim, 2006) were included. One SR concluded that laparoscopic techniques take longer than conventional techniques. LC implied a shorter hospital stay and greater comfort for the patient compared with open surgery. However, expertise played a key role in the results as both duration and complications were reduced when the treatment was performed by more experienced surgeons (ANDEM, 1994), (Treatment studies 2a).

Two SR evaluated the effectiveness, safety and postoperative recovery of LC compared with open and minilaparotomic cholecystectomy no difference was observed in postoperative symptomatic relief. The incidence of postoperative pain, morbidity and mortality were lower in patients who underwent LC than in those who underwent conventional open surgery. Postoperative ventilatory function was better in LC patients. No differences were observed with minilaparotomic cholecystectomy. The frequency of biliary complications was higher in LC than in both conventional and minilaparotomic procedures. The surgeons' training and expertise played a significant role in terms of surgical morbidity. Length of hospital stay was similar for both LC and minilaparotomic cholecystectomy but recovery time was slightly shorter for LC (Downs, 1996; Keus, 2006a). Other SR concluded that there are not differences between open and laparoscopic groups in terms of morbilidity, mortality and frequency of biliary complications, but hospital stay was lower in laparoscopic group (Keus, 2006b), (Treatment studies 1a).

A multicenter RCT comparing LC with minilaparotomic cholecystectomy concluded that LC entails longer operating time and a slightly shorter hospital stay (Elder, 1996). LC was associated only with shorter temporary disability ( 12.7 vs. 16.0 days, $p<0,001)$. Of note is the fact that the study may have been biased by differences in surgical experience using the two techniques since there were more experienced surgeons in the LC group (Elder, 1996), (Treatment studies 1b). Another RCT examining respiratory function in patients that had undergone laparoscopic or open cholecystectomy showed that ventilatory parameters were similar in both groups, being on average $40 \%$ worse than at baseline (Keus, 2006a), (Treatment studies $2 b$ ).

A cohort study that aimed to compare the results between expert surgeons and surgical trainees found no significant differences in either the conversion rate or the operating time (Elder, 1996). A similar study noted that mortality risk was lower with LC than with the open procedure (Zacks, 2002). A population-based study performed by the French Society of Endoscopic and Operative Radiology Surgery (SFERO) indicated a conversion rate of $6.9 \%$, a morbidity rate of $4.9 \%$ and a mortality rate of $0.2 \%$ (Collet, 1997), (Treatment studies 4). 
MANTEROLA, C.; PINEDA, V.; TORT, M.; TARGARONA, E.; VILLEGAS, P. R. \& ALONSO, P. Effectiveness of laparoscopic surgery for gallstones and and common bile duct lithiasis: a systematic overview. Int. J. Morphol., 28(3):729-742, 2010.

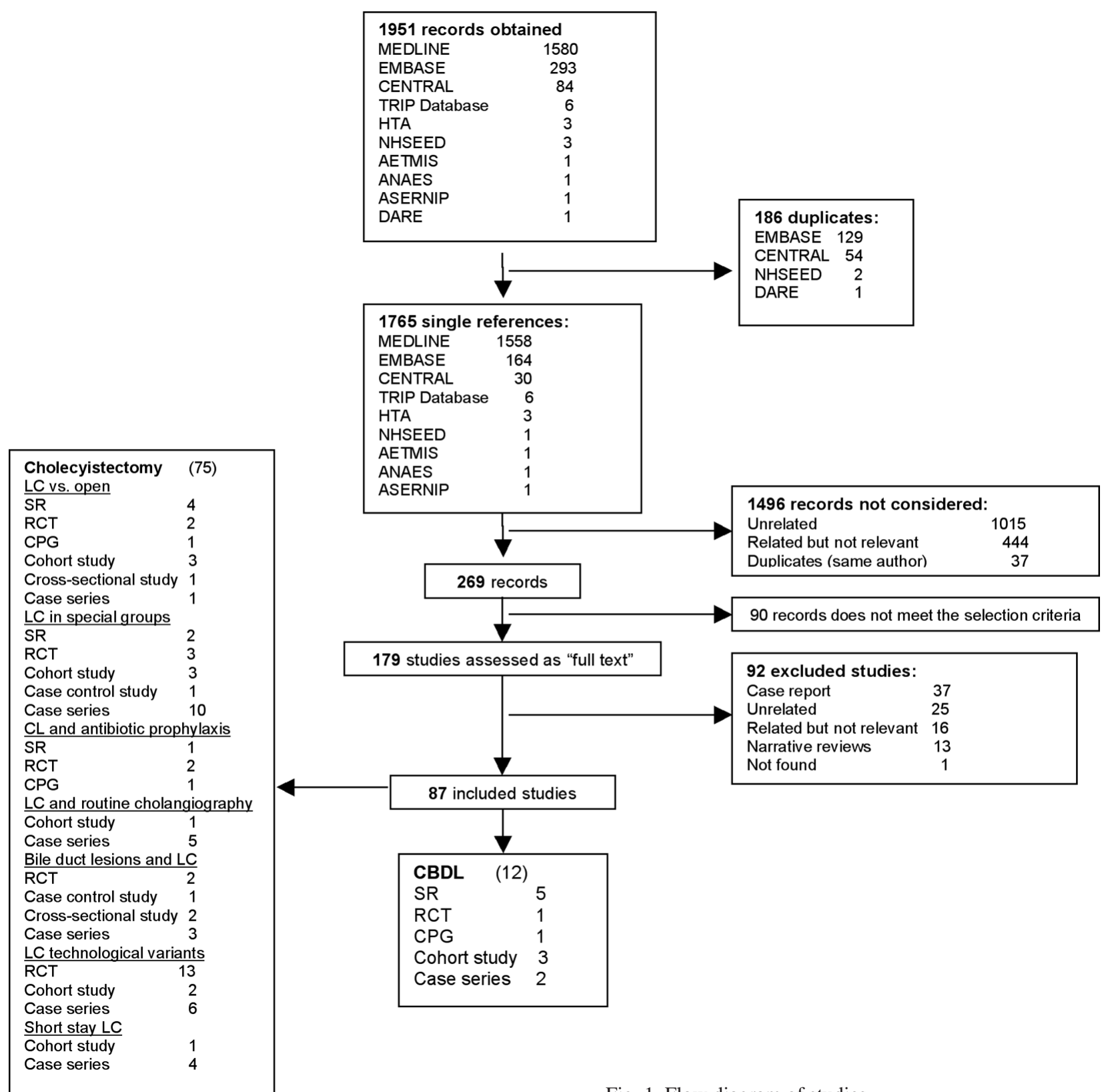

Fig. 1. Flow diagram of studies.

Following a SR of the evidence one clinical practice guideline (CPG) showed that LC improves quality of life sooner than open cholecystectomy. Nevertheless, long-term LC results were similar to the open procedure (Korolija, 2004), (Treatment studies 1a); and a prospective cohort supports the utility of LC by showing not only a significant reduction of GI postoperative symptoms but also marked improvement in patients' general QOL (Finan, 2006). (Treatment studies $2 b$ ).
Related with eventual risk factors for conversion to open surgery in patients undergoing laparoscopic cholecystectomy, a large prospective case series concluded that male gender, advanced age (over 60 years), higher body weight $>65 \mathrm{~kg}$, acute cholecystitis, previous upper abdominal surgery, junior surgeons, and diabetes associated with Hbalc $>6$. are variables to consider as potential associated factor (Ibrahim, 2006), (Treatment studies 4). 
Special groups of patients. Two SR, 3 RCTs, 3 cohort studies, 1 case-control study and 10 case series were found. The SR concluded that $\mathrm{LC}$ resulted in less postoperative pain, shorter hospital stay and fewer complications compared with the open approach in patients aged 65 or older (Weber, 2003), (Treatment studies 3a). Furthermore, a cohort study examining mortality rate for LC versus open cholecystectomy noted that the mortality rate was significantly reduced for LC in the subgroup of patients aged 70 to 79 (Feldman, 1994). In addition, a retrospective case series with patients aged 70 or over who underwent $L C$ noted found a shorter hospital stay, lower morbidity and mortality rates, and better postoperative recovery compared with the open technique (Perez Lara, 2006), (Treatment studies 4).

Assessment of two prospective case series including pregnant women with symptomatic and complicated cholecystolithiasis who underwent LC revealed no conversion or morbidity, faster recovery, and no complications among the infants. According to the authors, special care should be taken with the trocar position in women after their $32^{\text {nd }}$ week of pregnancy, a maximum pneumoperitoneum level of $10 \mathrm{mmHg}$ should be used and the routine intraoperative cholangiography (RIOC) should be avoided (Sungler, 2000; Daradkeh, 1999), (Treatment studies 4).

In patients with cirrhosis and portal hypertension Child A and B, one RCT found lower blood loss (75.5 vs. $112.5 \mathrm{~mL}, \mathrm{p}<0,001)$, lower morbidity $(13,2 \%$ vs. $30 \%, \mathrm{p}<$ $0,001)$ and shorter time to resume eating (18.3 vs. 44.2 hours, $\mathrm{p}<0,05)$ in the LC group compared with open surgery ( $\mathrm{Ji}$, 2005), (Treatment studies $2 b$ ). A case control study showed the conversion and morbidity rate was higher in the cirrhosis group than in the control group (Fernandes, 2000), (Treatment studies $3 b$ ); and two case series shows similar results than the previous RCT reported in patients with cirrhosis and portal hypertension Child A and B (Palanivelu, 2006; da Silveira, 2006).

A SR based on 5 RCT concluded that early laparoscopic cholecystectomy during acute cholecystitis is safe and provide shorter hospital stay (Gurusamy, 2006), (Treatment studies 1a). One RCT on acute cholecystitis (AC) compared safety and cost-effectiveness of urgent versus elective LC (use of percutaneous decompression prior to LC). Elective surgery did not show any advantages in terms of operating time, complication rate, blood loss, and conversion rate or hospital stay as compared with urgent LC (Sungler, 2000). Another low quality RCT comparing safety and results of LC vs. open surgery in patients with gangrenous $\mathrm{AC}$ found a similar operating duration and hospital stay but time to return to work was longer in the open group (Kiviluoto,
1998), (Treatment studies $2 b$ ). A retrospective cohort examining patients with $\mathrm{AC}$ who underwent open and laparoscopic procedures noted that LC was superior, with lower analgesic use, shorter hospital stay and less temporal disability (Glavic, 2001). A case series examining patients with AC, gallbladder gangrene, hydrops and gallbladder empyema observed a conversion rate of $20.5 \%$ and a morbidity of $17 \%$ (Eldar, 1998). A retrospective case series of LC for AC found similar results to those described for cholecystolithiasis, except in operating time and conversion rate which were significantly higher (Lujan, 1995), and another larger case series described statistical diferences of conversion rate between patients with $\mathrm{AC}$ vs. Chronic cholecystitis (20.6\% vs $4.2 \%)$ (Tan, 2006), (Treatment studies 4).

Several studies on the effectiveness of LC in chronic inflammation conditions, including Mirizzi syndrome, were also found. One cohort study comparing simple cholelithiasis and complicated cholelithiasis (Mirizzi syndrome and fistulae) groups found similar results in conversion rate and morbidity, and a longer operating time in the complicated cholelithiasis group (Perez-Morales, 2005). Case series showed widely variable results, with conversion rates ranging from $22.2 \%$ to $74 \%$ in patients with Mirizzi syndrome (Bagia, 2001; Schafer, 2003). One series reported a morbidity rate of $10.3 \% 44$ (Treatment studies 4).

Antibiotic prophylaxis. One SR, 2 RCTs and 1 CPG were found. One SR that included a meta-analysis concluded that the use of antibiotic prophylaxis for LC in low-risk patients did not reduce surgical wound infection or remote infection rates (Al-Ghnaniem, 2006), (Treatment studies 1a). One RCT showed similar results (Koc, 2003). Another low quality RCT comparing the use of antibiotic prophylaxis with mechanical prophylaxis (gallbladder removal with a polyethylene bag) observed a similar postoperative infection rate in both groups (Harling, 2000), (Treatment studies 2b). One CPG, currently under revision, evaluated the requirement of antibiotic prophylaxis in different types of surgery; it concluded that not only was prophylaxis not proven effective for this purpose but that its use may potentially increase hospital antibiotic use with little clinical benefit (SIGN, 2004).

Routine intraoperative cholangiography. Seven observational studies were found (one cohort study and 5 case series). One cohort study compared routine intraoperative cholangiography (RIOC) with selective cholangiography (in cases of suspected CBDL or unclear anatomy). RIOC did not improve the identification of hidden common bile duct (CBD) or reduce the number of bile duct injuries, and it lengthened operating time and increased associated costs (Ladocsi, 1997), (Diagnostic studies 3b). 
Retrospective case series observed an average time for RIOC of $12 \pm 9$ minutes, a conversion rate of $6.9 \%$, morbidity rate of $1.2 \%$, and retained CBD of $4 \%$ (Millat, 1997); but a large recently published case series observed $27,2 \%$ of abnormal cholangiograms in elective LC and $94.1 \%$ of abnormal cholangiograms in patients admitted with biliary emergencies, concluding that in their experience $10 \%$ of abnormal cholangiograms occurred in patients without preoperative risk factors for bile duct stones (Hamouda, 2007), (Diagnostic studies 3b). Another retrospective case series evaluated LC without RIOC but including selective preoperative endoscopic cholangiography, and observed that only $0.5 \%$ of all patients had retained stones (Thornton, 2002); another one suggest that selective intraoperative cholangiography would miss a proportion of patients with choledocholithiasis (Tan, 2006). Finally another case series recommended the use of routine laparoscopic ultrasound to reduce the need for intraoperative cholangiography during cholecystectomy, due to a $95 \%$ sensitivity, $100 \%$ specificity, $100 \%$ positive predictive value and $99.4 \%$ negative predictive value (Machi, 2007), (Diagnostic studies 3b).

Laparoscopic cholecystectomy related bile duct injuries. Cystic and hepatic duct lesions are among the most frequent complications of laparoscopic cholecystectomy (LC) (Kwon, 2001; Regoly-Merei, 1998; Targarona, 1998; Nuzzo, 2005), with values varying from $11.9 \%$ to $43 \%$ for morbidity and $1.7 \%$ to $12 \%$ for mortality (Regoly-Merei, 1998; Targarona, 1998; Sarmiento, 2004; Sicklick, 2005). Their incidence is approximately 0.31 to 1.34 per 1,000 cases. A survey was conducted among 1661 American surgeons to investigate the frequency of major bile duct injuries during LC. With a $45 \%$ response rate the prevalence of bile duct injuries was estimated to be around a third of procedures (34.1\%). Most complications occurred during the first 50 procedures which, despite the limitations of the report, suggest that most lesions are associated with inadequate expertise. Nevertheless, at least a third of those lesions might be associated with other factors such as those derived from inappropriate surgical maneuvers (Archer, 2001). A similar study with a $58 \%$ response rate observed $75.7 \%$ of major lesions, with no differences between the type of technique used or the use of RIOC (Nuzzo, 2005), (Treatment studies 4).

Regarding the repair of these lesions, two low quality RCT suggest that biliary stenting alone is as effective as biliary stenting with sphincterotomy in the treatment of uncomplicated post-laparoscopic cholecystectomy bile leaks (Mavrogiannis, 2006; Carr-Locke 2006), (Treatment studies $2 b)$. A prospective case series described the results of a number of major lesions requiring complex reconstruction such as hepaticojejunostomy. These lesions required a median of 9 days' hospital stay, and morbidity and mortality rates of $42.9 \%$ and $1.7 \%$ respectively were reported (Sicklick, 2005). One small case series that assessed laparoscopic repair of minor lesions reported that most of these only involved simple sutures associated with the endoscopic drainage (Kwon, 2001), (Treatment studies 4). One retrospective case series applied a quality-of-life questionnaire in 59 patients who had undergone surgical reconstruction after a bile duct lesion during $\mathrm{LC}$ and no differences between the patient and control groups were observed in any of the assessed domains (Sarmiento, 2004). Finally, a case control study comparing costs in a group of patients undergoing LC, with bile duct injuries, vs. a group of patients that had undergone cholecystectomy without lesions, did not find any significant differences in costs associated with bile duct injuries (Woods, 1996), (Treatment studies $3 b$ ).

Technological variants. Twenty one studies were found. 13 RCT, two cohort studies and 6 case series (four of them retrospective and two prospective). Routine intraoperative aspiration of gallbladder during laparoscopic cholecystectomy seems to be associated to less postoperative morbidity proportion respect to traditional LC (Calik, 2007). Undertaking LC without pneumoperitoneum is one of the multiple variants described for LC and is supported by two low quality RCTs (Kitano, 1993; Barczynski, 2004) and also by a retrospective case series (Nande, 2002). The reduction in the number of access ports (Trichak, 2003) and the use of 'mini-laparoscopy' and 'mini-instruments' is upheld by medium-quality RCTs and by a prospective case series (Nuzzo, 2005; Novitsky, 2005; Lai, 2003). The use of robotic systems is supported by a low quality RCT (Zhou, 2006). The use of neodynium YAG laser, which did not show any significant benefit over electrosurgery, is backed by two lowquality RCTs (Corbitt, 1991; Bordelon, 1993) and two case series (Lane, 1993; Mohiuddin, 2006). Ultrasound dissection, which might imply benefits over conventional electroscalpel dissection, is supported by two medium-quality RCTs (Janssen, 2003; Cengiz, 2005). Gallbladder dissection with bipolar cautery scissors, a variant that was not superior to monopolar scissors, is supported by a low-quality RCT (Edelman, 1995). In two low-quality RCT assistance with a water irrigation system and a hydrodissection with adrenaline-lidocaine-saline solution, as an alternative to dissection, showed clinically modest results (Shekarriz, 2003) and no differences respect to traditional dissection system (Caliskan, 2006). The use of various types of ligature and suture as an alternative to conventional stapling is supported by a retrospective cohort81 and two retrospective case series (Yano, 2003; Yeh, 2004). Finally, the use of $0.5 \%$ bupivacaine-soaked Surgicel in the gallbladder proved in a cohort study, appear to be effective for control visceral pain after laparoscopic cholecystectomy, but port-site infiltration 
alone would be ineffective (Verma, 2006), (Treatment studies $2 b$ and 4$)$.

Laparoscopic cholecystectomy as short-stay major surgery. In the 90s, LC was regarded as a way to reduce hospital stay in patients undergoing cholecystectomy (Verma, 2006). However, this potential benefit of LC with early discharge versus the standard protocol is supported only by observational studies with non-conclusive results (Grace, 1991; Martinez Vieira, 2004; Lau, 2002; Pattillo, 2004; Bueno Lledo, 2006), (Treatment studies 4).

\section{Effectiveness of laparoscopic treatment for common bile duct lithiasis.}

The ideal treatment for CBDL remains controversial. Options vary from endoscopic papillotomy to laparotomic or laparoscopic choledochotomy, including bile duct exploration via the cystic duct (Paganini, 2007). CBDL treatment has mainly been undertaken by endoscopy prior to LC. This strategy appears to resolve CBDL in most cases but is likely to find no evidence of the presence of a stone in $20-60 \%$ of patients and is associated with a considerable morbidity risk (Paganini, 2007; Smith, 1997; Joyce, 1991; Prat, 1996; Costi, 2007; Trondsen, 1998).

There are also reports on primary choledochorraphy versus choledochorraphy with a Kehr tube or modified biliary endoprosthesis. It is generally accepted that two-stage surgery (endoscopic papillotomy followed by LC) is the most appropriate strategy for high-risk patients, such as those with cholangitis and pancreatitis (Liu, 2001). However, for low risk patients, a one-step strategy has progressively been adopted in clinical practice, this involves LC and laparoscopic bile duct exploration (transcystic or via choledochotomy). There is yet no specified algorithm for the laparoscopic treatment of CBDL (Cuschieri, 1999; Wei, 2003), and this uncertainty become evident in the findings of the 5 available SRs (Martin, 2006; Pichon Riviere, 2005; Tranter, 2002; Vial, 2005; Clayton, 2006).

The Institute for Health and Clinical Effectiveness report concludes that effectiveness of bile duct laparoscopic exploration is very high (90\% in most studies) and similar to that of endoscopic treatment. Endoscopic morbidity is about $8 \%$ and is related to the procedure (pancreatitis, perforation and bleeding). Morbidity of bile duct laparoscopic exploration includes the risk of incomplete stone $(5 \%)$ or stricture removal (3\%), and the need for conversion to open surgery (4\%). Disadvantages of the laparoscopic method include the need for highly trained surgeons and specific equipment (Pichon Riviere, 2005), (Treatment studies 1a).
Three SRs comparing endoscopic treatment with surgical treatment of CBDL (open and laparoscopic) have recently been published (Martin, 2006; Pichon Riviere, 2005; Tranter, 2002; Vial, 2005). These reviews conclude that bile duct laparotomic exploration is more effective than endoscopic treatment for bile duct cleaning. Endoscopic treatment requires a higher number of procedures per patient and a longer hospital stay and is at least as safe and effective. Nevertheless, no clear advantages, in terms of lack of response to treatment, morbidity or mortality have been observed (Martin, 2006; Pichon Riviere, 2005; Tranter, 2002; Vial, 2005), (Treatment studies 1a).

Another SR comparing endoscopic and surgery vs. surgery alone for CBDL treatment with the gallbladder in situ, verified that there was no significant difference in successful duct clearance, mortality, morbidity between the endoscopic and surgical groups. There was also no significant difference between the endoscopic and laparoscopic surgery groups. So authors concluded that both approaches have similar outcomes, and treatment should be determined by local resources and expertise (Clayton, 2006), (Treatment studies 1a).

On the other hand, a recently published low-quality RCT compare success rate, length of hospital stay, clinical results, and costs of sequential treatment (ERCP followed by LC) vs. the laparoendoscopic rendezvous in patients with CBDL and verified that laparoendoscopic rendezvous technique allows a higher rate of CBDL clearance, shorter hospital stay and cost reduction respect the ERCP followed by LC group (Morino, 2006), (Treatment studies $2 b$ ).

Another aspect to consider is bile duct drainage via choledochotomy plus ulterior choledochorraphy with a Kehr tube. One recent published SR tried to assess the benefits and harms of routine primary closure versus Ttube drainage following laparoscopic common bile duct stone exploration and concluded that there is insufficient evidence to recommend T-tube drainage or primary closure after laparoscopic common bile duct stone exploration (Gurusamy, 2007), (Treatment studies 1a). Other studies available to date on this subject are observational [three cohort studies (Griniatsos, 2005; KimK, 2004; Lien, 2005) and two case series (Decker, 2003; Fanelli, 2001)] and their results support the use of biliary endoprosthesis after bile duct laparoscopic exploration as a safe, quick and effective alternative. Biliary endoprosthesis is a minimally invasive therapy that implies a shorter hospital stay and seems to reduce morbidity after the insertion of a Kehr tube (Griniatsos, 2005; KimK, 2004; Lien, 2005; Decker, 2003; Fanelli, 2001), (Treatment studies 4). 


\section{DISCUSSION}

Following the great technological advances that have occurred in recent years laparoscopic treatment is generally considered a quick and safe procedure. A high level of training in the procedure is required, however, and the number of complications appears to decrease as experience increases. In this overview, LC for patients with cholecystolithiasis and acute cholecystitis is associated with a longer operating time, a shorter hospital stay and a better postoperative quality of life in comparison with open surgery. Although it is a relatively safe procedure, there is a higher risk of bile duct injuries and complex repair surgery is often required. (High quality evidence). LC seems a relatively safe procedure for special groups of patients such as the elderly, pregnant women or patients with cirrhosis and portal hypertension Child A y B (Low quality evidence) (ANDEM, 1994; Downs, 1996; Korolija, 2004; Mimica, 2000; Ros,

Table I. Evidence Table.

\begin{tabular}{|c|c|c|c|}
\hline Clinical question & Number of studies & $\begin{array}{l}\text { Quality of the } \\
\text { evidence }\end{array}$ & Summary of findings \\
\hline \multirow[t]{2}{*}{ LC vs. open cholecystectomy. } & \multirow{2}{*}{$\begin{array}{l}4 \mathrm{SRs} \\
2 \mathrm{RCTs} \\
3 \mathrm{Cohort} \text { studies } \\
1 \mathrm{CPG} \\
1 \mathrm{C} \text { ross-sectional } \\
\text { study } \\
1 \text { case series }\end{array}$} & High & $\begin{array}{l}\text { LC is associated with longer operating time, a shorter } \\
\text { hospital stay and a better postoperative course for patients } \\
\text { with cholecystolithiasis. }\end{array}$ \\
\hline & & Low & $\begin{array}{l}\text { LC can be a safe procedure for special groups of patients } \\
\text { such as the elderly, pregnant women and patients with } \\
\text { cirrhosis and portal hypertension Child A y B. }\end{array}$ \\
\hline \multirow[t]{3}{*}{$\begin{array}{l}\text { LC in special groups of } \\
\text { patients. }\end{array}$} & \multirow{3}{*}{$\begin{array}{l}2 \mathrm{SR} \\
3 \mathrm{RCTs} \\
3 \text { Cohort studies } \\
1 \mathrm{C} \text { ase control } \\
\text { studies } \\
10 \text { case series }\end{array}$} & Moderate & $\begin{array}{l}\text { LC results in less postoperative pain, shorter hospital stay } \\
\text { and fewer complications compared with open approach in } \\
\text { patients aged } 65 \text { and older. }\end{array}$ \\
\hline & & Moderate & $\begin{array}{l}\text { LC is a safe procedure in patients with acute } \\
\text { cholecystitis. }\end{array}$ \\
\hline & & Low & $\begin{array}{l}\text { It has shown to be a safe procedure for special groups of } \\
\text { patients such as the elderly, pregnant women and patients } \\
\text { with cirrhosis and portal hypertension Child A y B. }\end{array}$ \\
\hline $\begin{array}{l}\text { Use of antibiotic prophylaxis } \\
\text { for } L C \text {. }\end{array}$ & $\begin{array}{l}1 \mathrm{SR} \\
2 \mathrm{RCTs} \\
1 \mathrm{CPG}\end{array}$ & High & $\begin{array}{l}\text { Use of antibiotic prophylaxis in low-risk patients } \\
\text { undergoing a LC does not offer any additional benefits in } \\
\text { terms of reduction of postoperative infection rates. }\end{array}$ \\
\hline $\begin{array}{l}\text { Use of routine intra operative } \\
\text { cholangiography during } L C .\end{array}$ & $\begin{array}{l}1 \text { Cohort studies } \\
5 \text { case series }\end{array}$ & Low & $\begin{array}{l}\text { There is scarce evidence about the need of RIOC during } \\
\text { LC and results do not support its use. }\end{array}$ \\
\hline LC-related bile duct injuries. & $\begin{array}{l}1 \mathrm{C} \text { ase control } \\
\text { studies } \\
2 \mathrm{C} \text { ross-sectional } \\
\text { studies } \\
3 \text { case series }\end{array}$ & Moderate & $\begin{array}{l}\text { Higher risk of bile duct injuries mainly associated with } \\
\text { experience, which often requires more complex repair } \\
\text { surgeries. }\end{array}$ \\
\hline $\begin{array}{l}\text { Technological variants for } \\
\text { LC. }\end{array}$ & $\begin{array}{l}13 \text { RCTs } \\
2 \text { Cohort studies } \\
6 \text { case series }\end{array}$ & Low & $\begin{array}{l}\text { Multiple variants for LC have been described; however, } \\
\text { there is little evidence for their effectiveness. }\end{array}$ \\
\hline $\begin{array}{l}\text { LC as short-stay major } \\
\text { surgery. }\end{array}$ & $\begin{array}{l}1 \text { Cohort studies } \\
4 \text { case series }\end{array}$ & Low & No evidence of major complications of outpatient LC. \\
\hline \multirow{2}{*}{$\begin{array}{l}\text { Effectiveness of laparoscopic } \\
\text { treatment for common bile } \\
\text { duct lithiasis. }\end{array}$} & $\begin{array}{l}5 \mathrm{SR} \\
1 \mathrm{RCT}\end{array}$ & High & $\begin{array}{l}\text { Two-stage surgery is the most appropriate strategy for } \\
\text { high-risk patients. }\end{array}$ \\
\hline & $\begin{array}{l}1 \mathrm{CPG} \\
3 \text { Cohort studies } \\
3 \text { case series }\end{array}$ & Low & $\begin{array}{l}\text { One-time laparoscopic treatment has been incorporated } \\
\text { for low-risk patients. Use of biliary endoprosthesis after } \\
\text { bile duct laparoscopic exploration may be as afe, } \\
\text { effective alternative as compared with the implantation of } \\
\text { a Kehr drainage. }\end{array}$ \\
\hline
\end{tabular}

LC: laparoscopic cholecystectomy; SR: systematic reviews; RCT: randomised clinical trial; CPG: clinical practice guideline; RIOC: routine intraoperative cholangiography.

High quality: it is very unlikely that future studies change our confidence in the estimate of effect and therefore our confidence is high. Moderate quality: it is likely that future studies change our confidence in the estimate of effect. Low quality: it very likely that future studies change our confidence in the estimate of effect, therefore our confidence is low. 
2001; Elder, 1996; Finan, 2006; Zacks, 2002; Collet, 1997; Ibrahim, 2006; Weber, 2003; Feldman, 1994; Perez Lara, 2006; Sungler, 2000; Daradkeh, 1999; Ji, 2005; Fernandes, 2000; Palanivelu, 2006; da Silveira, 2006; Gurusamy, 2006; Chandler, 2000; Kiviluoto, 1998; Glavic, 2001; Eldar, 1998; Lujan, 1995; Tan, 2006; Perez-Morales, 2005; Bagia, 2001; Schafer, 2003; Kwon, 2001; Woods, 1996).

Antibiotic prophylaxis in low-risk patients undergoing LC does not offer any additional benefits in terms of reduction of postoperative infection rates (High quality evidence). There is little available evidence on the need for routine intraoperative cholangiography during LC and results so far do not support its use (Low quality evidence). Several variants of LC have been described, but evidence about their effectiveness is scarce (Low quality evidence). On the other hand, there is no evidence of major complications with outpatient LC (Low quality evidence) (Al-Ghnaniem, 2003; Koc, 2003; Harling, 2000; SIGN, 2004; Ladocsi, 1997; Millat, 1997; Thornton, 2002; Kitano, 1993; Barczynski, 2004; Nande, 2002; Trichak, 2003; Novitsky, 2005; Lai, 2003; Zhou, 2006; Corbitt, 1991; Bordelon, 1993; Lane GE, 1993; Janssen, 2003; Cengiz, 2005; Edelman, 1995; Shekarriz, 2003; Bencini, 2003; Yano, 2003; Verma, 2006; Grace, 1991; Martinez Vieira, 2004; Lau, 2002; Pattillo, 2004; Bueno Lledo, 2006).

Regarding laparoscopic treatment for CBDL the available evidence suggests that two-stage surgery is the most appropriate strategy for high-risk patients (High quality evidence). For low-risk patients the one-step laparoscopic treatment has progressively been incorporated into clinical practice. Furthermore, the use of biliary endoprosthesis after bile duct laparoscopic exploration may be a safe and effective alternative as compared with the implantation of a Kehr tube (Low quality evidence) (Smith, 1997; Joyce, 1991; Prat, 1996; Costi, 2007; Trondsen, 1998; Liu, 2001; Cuschieri, 1999; Wei, 2003; Gurusamy, 2007; Griniatsos, 2005; KimK, 2004; Lien, 2005; Decker, 2003; Fanelli, 2001).

From the present overview we can conclude that studies with a better methodological quality are warranted to assess the issues reported here. In the LC context, the effectiveness and safety of laparoscopic therapy versus conventional surgery should be assessed in low-risk patients. Other issues yet to be clarified are the need or not for antibiotic prophylaxis in high-risk patients and the costeffectiveness of LC and its different technological variants. For CBDL, the effectiveness and safety of laparoscopic treatment versus conventional surgery in low-risk patients should be established. Finally, the effectiveness and safety of one-time laparoscopic treatment versus two-stage surgery in low-risk patients and also the effectiveness of choledochorraphy without endoprosthesis should be determined (Table I).

Despite the wide implementation of laparoscopic procedures the available evidence for their effectiveness in the treatment of gallstones and CBDL is scarce and of low methodological quality. Adequately powered head-tohead studies are warranted in order to clarify these issues. These trials should have a rigorous design with participants being randomised to clinicians who will only undertake the intervention they are expert in (Howes, 1997).

\section{ACKNOWLEDGEMENTS}

This overview was conducted under the direction of the Andalusian Agency for Health Technology Assessment within the collaboration framework established in the National Health System Quality Plan, thanks to the agreement between the Carlos III Institute (Ministry of Health) and the Foundation Progress and Health.

We would like to express our gratitude to Carolyn Newey for her help reviewing and editing of this overview.

MANTEROLA，C.; PINEDA， V.; TORT，M.; TARGARONA, E.; VILLEGAS, P. R. \& ALONSO, P. Efectividad de la cirugía laparoscópica para colecistolitiasis y coledocolitiasis: Revisión global de la evidencia. Int. J. Morphol., 28(3):729-742, 2010.

RESUMEN: El objetivo del presente estudio fue evaluar la evidencia disponible respecto de la efectividad de la cirugía laparoscópica en el tratamiento de la colelitiasis y la litiasis de la vía biliar (LVBP). Para ello, se realizó una revisión global de la evidencia disponible. Se realizaron búsquedas en las bases de datos MEDLINE, EMBASE y The Cochrane Library (1998-2008). Se incluyeron guías de práctica clínica (GPC), revisiones sistemáticas (RS), ensayos clínicos con asignación aleatoria (EC) y estudios observacionales. Se valoró la validez interna y la calidad global de los estudios. Los datos disponibles y la evidencia generada se clasificaron en base a la propuesta del Centro de Oxford de Medicina Basada en la Evidencia. 87 estudios fueron incluidos en esta revisión (3 GPC, 12 RS, 23 EC, 13 estudios de cohortes, 3 estudios transversales, 2 estudios de casos y de controles y 31 series de casos). En comparación con la colecistectomía abierta, la colecistectomía laparoscópica (CL) se asocia con menor tiempo operatorio y estancia hospitalaria y mejor calidad de vida (evidencia de alta calidad). El uso de profilaxis antibiótica no parece reducir la tasa de infección en pacientes de bajo riesgo (evidencia de alta calidad). Aunque se han descrito numerosas técnicas para realizar una CL, su eficacia no es aún concluyente (evidencia de baja 
calidad). La cirugía en dos etapas es la estrategia más adecuada para los pacientes de alto riesgo con LVBP (evidencia de alta calidad). La mortalidad del tratamiento laparoscópico de la LVBP es similar a la de la cirugía abierta; y como su eficacia es similar a la del tratamiento endoscópico (evidencia de alta calidad). Se puede concluir señalando que la evidencia disponible respecto de la efectividad de la cirugía laparoscópica para el tratamiento de la colelitiasis y la LVBP es escasa y de baja calidad metodológica; y que se requieren estudios de mejor calidad para valorar de forma más apropiada estas técnicas.

PAlABRAS CLAVE: Colelitiasis; Colecistolitiasis; Coledocolitiasis; Cálculos biliares; Laparoscopia; Colecistectomía laparoscópica; Evaluación de tecnología sanitaria.

\section{REFERENCES}

Al-Ghnaniem, R.; Benjamin, I.S. \& Patel A.G. Meta-analysis suggests antibiotic prophylaxis is not warranted in lowrisk patients undergoing laparoscopic cholecystectomy. Br. J. Surg., 90:365-66, 2003.

A.N.D.E.M. Agence Nationale pour le Développement de l'Évaluation Médicale. Evaluation des methodes coelioscopiques en chirurgie digestive, 1994.

Archer, S. B.; Brown, D. W.; Smith, C. D.; Branum, G. D. \& Hunter, J. G. Bile duct injury during laparoscopic cholecystectomy: results of anational survey. Ann. Surg., 234:549-58, 2001.

Bagia, J. S.; North, L. \& Hunt, D. R. Mirizzi syndrome: an extra hazard for laparoscopic surgery. ANZ J. Surg., 71:394-97, 2001.

Barczynski, M. \& Herman, R. M. Low-pressure pneumoperitoneum combined with intraperitoneal saline washout for reduction of pain after laparoscopic cholecystectomy: A prospective randomized study. Surg. Endosc., 18:1368-73, 2004.

Bencini, L.; Boffi, B.; Farsi, M.; Sanchez, L. J.; Scatizzi; M. \& Moretti R. Laparoscopic cholecystectomy: retrospective comparative evaluation of titanium versus absorbable clips. J. Laparoendosc. Adv. Surg. Tech. A, 13:93-8, 2003.

Bordelon, B. M.; Hobday, K. A. \& Hunter, J. G. Laser vs electrosurgery in laparoscopic cholecystectomy. A prospective randomized trial. Arch. Surg., 128:233-6, 1993.
Bueno Lledo, J.; Planells Roig, M.; Arnau Bertomeu, C.; Sanahuja Santafe, A.; Oviedo Bravo, M.; Garcia Espinosa, R.; Marti Obiol, R. \& Espi Salinas, A. Outpatient laparoscopic cholecystectomy: a new gold standard for cholecystectomy. Rev. Esp. Enferm. Dig., 98:14-24, 2006.

Calik, A.; Topaloglu, S.; Topcu, S.; Turkyilmaz, S.; Kucuktulu, U. \& Piskin B. Routine intraoperative aspiration of gallbladder during laparoscopic cholecystectomy. Surg. Endosc., 21:1578-81, 2007.

Caliskan, K.; Nursal, T. Z. \& Yildirim, S. Hydrodissection with adrenaline-lidocaine-saline solution in laparoscopic cholecystectomy. Langenbecks Arch. Surg., 391:359-63, 2006.

Carr-Locke, A. D. 'Biliary stenting alone versus biliary stenting plus sphincterotomy for the treatment of postlaparoscopic cholecystectomy bile leaks'. Eur. J. Gastroenterol. Hepatol., 18:1053-5, 2006.

Cengiz, Y.; Janes, A.; Grehn, A. \& Israelsson, L. A. Randomized trial of traditional dissection with electrocautery versus ultrasonic fundus-first dissection in patients undergoing laparoscopic cholecystectomy. $\mathrm{Br}$. J. Surg., 92:810-3, 2005.

Chandler, C. F.; Lane, J. S.; Ferguson, P.; Thompson, J. E. $\&$ Ashley, S. W. Prospective evaluation of early versus delayed laparoscopic cholecystectomy for treatment of acute cholecystitis. Am. Surg., 66:896-900, 2000.

Clayton, E. S.; Connor, S.; Alexakis, N. \& Leandros, E. Metaanalysis of endoscopy and surgery versus surgery alone for common bile duct stones with the gallbladder in situ. Br. J. Surg., 93:1185-91, 2006.

Collet, D. Laparoscopic cholecystectomy in 1994. Results of a prospective survey conducted by SFCERO on 4,624 cases. Societe Francaise de Chirurgie Endoscopique et Radiologie Operatoire. Surg. Endosc., 11:56-63, 1997.

Corbitt J. D. Jr. Laparoscopic cholecystectomy: laser versus electrosurgery. Surg. Laparosc. Endosc., 1:85-8, 1991.

Costi, R.; DiMauro, D. \& Mazzeo, A. Routine laparoscopic cholecystectomy after endoscopic sphincterotomy for choledocholithiasis in octogenarians: is it worth the risk? Surg. Endosc., 21:41-7, 2007.

Cuschieri, A.; Lezoche, E.; Morino, M.; Croce, E.; Lacy, A. $\&$ Toouli, J. E.A.E.S. multicenter prospective 
randomized trial comparing two-stage vs single-stage management of patients with gallstone disease and ductal calculi. Surg. Endosc., 13:952-7, 1999.

Daradkeh, S.; Sumrein, I.; Daoud, F.; Zaidin, K. \& AbuKhalaf, M. Management of gallbladder stones during pregnancy: conservative treatment or laparoscopic cholecystectomy? Hepatogastroenterology, 46:30746, 1999.

da Silveira, E. B. Outcome of cirrhotic patients undergoing cholecystectomy: applying Bayesian analysis in gastroenterology. J. Gastroenterol. Hepatol., 21:95862, 2006.

Decker, G.; Borie, F.; Millat, B.; Berthou, J. C.; Deleuze, A. \& Drouard, F. One hundred laparoscopic choledochotomies with primary closure of the common bile duct. Surg. Endosc., 17:12-8, 2003.

Devereaux, P. J.; Bhandari, M.; Clarke, M.; Montori, V. M.; Cook, D. J. \& Yusuf, S. Need for expertise-based randomised controlled trials. BMJ, 330(7482):88, 2005.

Downs, S. H. Systematic review of the effectiveness and safety of laparoscopic cholecystectomy. Ann. R. Coll. Surg. Engl., 78(3 Part 2):241-323, 1996.

Edelman, D. S. \& Unger, S. W. Bipolar versus monopolar cautery scissors for laparoscopic cholecystectomy: a randomized, prospective study. Surg. Laparosc. Endosc., 5:459-62, 1995.

Elder, S.; Kunin, J.; Chouri, H.; Sabo, E.; Matter, I.; Nash, E. \& Schein, M. Safety of laparoscopic cholecystectomy on a teaching service: a prospective trial. Surg. Laparosc. Endosc., 6:218-20, 1996.

Elder, S.; Sabo, E.; Nash, E.; Abrahamson, J. \& Matter, I. Laparoscopic cholecystectomy for the various types of gallbladder inflammation: a prospective trial. Surg. Laparosc. Endosc., 8:200-7, 1998.

Fanelli, R. D. \& Gersin, K. S. Laparoscopic endobiliary stenting: a simplified approach to the management of occult common bile duct stones. J. Gastrointest. Surg., 5:74-80, 2001.

Feldman, M. G.; Russell, J. C.; Lynch, J. T. \& Mattie, A. Comparison of mortality rates for open and closed cholecystectomy in the elderly: Connecticut statewide survey. J. Laparoendosc. Surg., 4:165-72, 1994.
Fernandes, N. F.; Schwesinger, W. H. \& Hilsenbeck, S. G. Laparoscopic cholecystectomy and cirrhosis: a case-control study of outcomes. Liver Transpl., 6:340-4, 2000.

Finan, K. R.; Leeth, R. R.; Whitley, B. M.; Klapow, J. C. \& Hawn, M. T. Improvement in gastrointestinal symptoms and quality of life after cholecystectomy. Am. J. Surg., 192:196-202, 2006.

Glavic, Z.; Begic, L.; Simlesa, D. \& Rukavina, A. Treatment of acute cholecystitis. A comparison of open vs laparoscopic cholecystectomy. Surg. Endosc., 15:398401, 2001.

Grace, P. A.; Quereshi, A.; Coleman, J.; Keane, R.; McEntee, G. \& Broe, P. Reduced postoperative hospitalization after laparoscopic cholecystectomy. Br. J. Surg., 78:160-2, 1991.

Griniatsos, J.; Karvounis, E.; Arbuckle, J. \& Isla, A. M. Costeffective method for laparoscopic choledochotomy. ANZ J. Surg., 75:35-8, 2005.

Gurusamy, K. S. \& Samraj, K. Early versus delayed laparoscopic cholecystectomy for acute cholecystitis. Cochrane Database Syst. Rev., (4):CD005440, 2006.

Gurusamy, K. \& Samraj, K. Primary closure versus T-tube drainage after laparoscopic common bile duct stone exploration. Cochrane Database Syst. Rev., (1):CD005641, 2007.

Guyatt, G.; Gutterman, D.; Baumann, M. H.; AddrizzoHarris, D.; Hylek, E. M. \& Phillips, B. Grading strength of recommendations and quality of evidence in clinical guidelines: report from an american college of chest physicians task force. Chest, 129:174-81, 2006.

Hamouda, A. H.; Goh, W.; Mahmud, S.; Khan, M. \& Nassar, A. H. Intraoperative cholangiography facilitates simple transcystic clearance of ductal stones in units without expertise for laparoscopic bile duct surgery. Surg. Endosc., 21:955-99, 2007.

Harling, R.; Moorjani, N.; Perry, C.; MacGowan, A. P. \& Thompson, M. H. A prospective, randomised trial of prophylactic antibiotics versus bag extraction in the prophylaxis of wound infection in laparoscopic cholecystectomy. Ann. R. Coll. Surg. Engl., 82:408-10, 2000 .

Howes, N.; Chagla, L.; Thorpe, M. \& McCulloch, P. Surgical practice is evidence based. Br. J. Surg., 84:1220-3, 1997. 
Ibrahim, S.; Hean, T. K.; Ho, L. S.; Ravintharan, T.; Chye, T. N. \& Chee, C. H. Risk factors for conversion to open surgery in patients undergoing laparoscopic cholecystectomy. World J. Surg., 30:1698-704, 2006.

Janssen, I. M.; Swank, D. J.; Boonstra, O.; Knipscheer, B. C.; Klinkenbijl, J. H. \& van Goor, H. Randomized clinical trial of ultrasonic versus electrocautery dissection of the gallbladder in laparoscopic cholecystectomy. $\mathrm{Br}$. J. Surg., 90:799-803, 2003.

Jaffray, B. Minimally invasive surgery. Arch. Dis. Child, 90:537-42, 2005.

Ji, W.; Li, L. T.; Wang, Z. M.; Quan, Z. F.; Chen, X. R. \& Li, J. S. A randomized controlled trial of laparoscopic versus open cholecystectomy in patients with cirrhotic portal hypertension. World J. Gastroenterol., 11:2513-17, 2005.

Joyce, W. P.; Keane, R.; Burke, G. J.; Daly, M.; Drumm, J.; Egan, T. J. 6 Delaney, P. V. Identification of bile duct stones in patients undergoing laparoscopic cholecystectomy. Br. J. Surg., 78:1174-6, 1991.

Keus, F.; de Jong, J. A.; Gooszen, H. G. \& van Laarhoven, C. J. Laparoscopic versus open cholecystectomy for patients with symptomatic cholecystolithiasis. Cochrane Database Syst. Rev., (4):CD006231, 2006.

Keus, F.; de Jong, J. A.; Gooszen, H. G. \& van Laarhoven, C. J. Laparoscopic versus small-incision cholecystectomy for patients with symptomatic cholecystolithiasis. Cochrane Database Syst. Rev., (4):CD006229, 2006.

Korolija, D.; Sauerland, S.; Wood-Dauphinee, S.; Abbou, C. C.; Eypasch, E. \& Caballero, M. G. Evaluation of quality of life after laparoscopic surgery: evidence-based guidelines of the European Association for Endoscopic Surgery. Surg. Endosc., 18:879-97, 2004.

Kim, E. K. \& Lee, S. K. Laparoscopic treatment of choledocholithiasis using modified biliary stents. Surg. Endosc., 18:303-6, 2004.

Kitano, S.; Iso, Y.; Tomikawa, M.; Moriyama, M. \& Sugimachi, K. A prospective randomized trial comparing pneumoperitoneum and U-shaped retractor elevation for laparoscopic cholecystectomy. Surg. Endosc., 7:311-4, 1993.

Kiviluoto, T.; Siren, J.; Luukkonen, P. \& Kivilaakso, E.
Randomised trial of laparoscopic versus open cholecystectomy for acute and gangrenous cholecystitis. Lancet, 1(9099):321-5, 1998.

Koc, M.; Zulfikaroglu, B.; Kece, C. \& Ozalp, N. A prospective randomized study of prophylactic antibiotics in elective laparoscopic cholecystectomy. Surg. Endosc., 17:1716-8, 2003.

Kwon, A. H.; Inui, H. \& Kamiyama, Y. Laparoscopic management of bile duct and bowel injury during laparoscopic cholecystectomy. World J. Surg., 25:85661, 2001.

Ladocsi, L. T.; Benitez, L. D.; Filippone, D. R. \& Nance, F. C. Intraoperative cholangiography in laparoscopic cholecystectomy: a review of 734 consecutive cases. Am. Surg., 63:150-6, 1997.

Lai, E. C.; Fok, M. \& Chan, A. S. Needlescopic cholecystectomy: prospective study of 150 patients. Hong Kong Med. J., 9:238-42, 2003.

Lane, G. E. \& Lathrop, J. C. Comparison of results of KTP/ 532 laser versus monopolar electrosurgical dissection in laparoscopic cholecystectomy. J. Laparoendosc. Surg., 3:209-14, 1993.

Lau, H. \& Brooks, D. C. Transitions in laparoscopic cholecystectomy: the impact of ambulatory surgery. Surg. Endosc., 16:323-6, 2002.

Lien, H. H.; Huang, C. C.; Huang, C. S.; Shi, M. Y.; Chen, D. F.; Wang, N. Y. \& Tai, F. C. Laparoscopic common bile duct exploration with T-tube choledochotomy for the management of choledocholithiasis. $J$. Laparoendosc. Adv. Surg. Tech. A, 15:298-302, 2005.

Litynski, G. S. Profiles in laparoscopy: Mouret, Dubois, and Perissat: the laparoscopic breakthrough in Europe (19871988). JSLS, 3:163-7, 1999.

Liu, T. H.; Consorti, E. T.; Kawashima, A.; Tamm, E. P.; Kwong, K. L. \& Gill, B. S. Patient evaluation and management with selective use of magnetic resonance cholangiography and endoscopic retrograde cholangiopancreatography before laparoscopic cholecystectomy. Ann. Surg., 234:33-40, 2001.

Lujan, J. A.; Parrilla, P.; Robles, R.; Torralba, J. A.; Garcia Ayllon, J.; Liron, R. \& Sanchez-Bueno, F. Laparoscopic cholecystectomy in the treatment of acute cholecystitis. J. Am. Coll. Surg., 181:75-7, 1995. 
Machi, J.; Oishi, A. J.; Tajiri, T.; Murayama, K. M.; Furumoto, N. L. \& Oishi, R. H. Routine laparoscopic ultrasound can significantly reduce the need for selective intraoperative cholangiography during cholecystectomy. Surg. Endosc., 21:270-4, 2007.

Martin, D. J.; Vernon, D. R. \& Toouli, J. Surgical versus endoscopic treatment of bile duct stones. Cochrane Database Syst. Rev., (2):CD003327, 2006.

Martinez Vieira, A.; Docobo Durantez, F.; Mena Robles, J.; Duran Ferreras, I.; Vazquez Monchul, J.; Lopez Bernal, F. \& Romero Vargas, E.Laparoscopic cholecystectomy in the treatment of biliary lithiasis: outpatient surgery or short stay unit? Rev. Esp. Enferm. Dig., 96:452-5, 4569, 2004.

Mavrogiannis, C.; Liatsos, C.; Papanikolaou, I. S.; Karagiannis, S.; Galanis, P. \& Romanos, A. Biliary stenting alone versus biliary stenting plus sphincterotomy for the treatment of post-laparoscopic cholecystectomy biliary leaks: a prospective randomized study. Eur. J. Gastroenterol. Hepatol., 18:405-9, 2006.

Matthews, J. B. Minimally invasive surgery: how goes the revolution? Gastroenterology, 116:513, 1999.

Millat, B.; Deleuze, A.; de Saxce, B.; de Seguin, C. \& Fingerhut, A. Routine intraoperative cholangiography is feasible and efficient during laparoscopic cholecystectomy. Hepatogastroenterology, 44:22-7, 1997.

Mimica, Z.; Biocic, M.; Bacic, A.; Banovic, I.; Tocilj, J. \& Radonic, V. Laparoscopic and laparotomic cholecystectomy: a randomized trial comparing postoperative respiratory function. Respiration, 67:153-8, 2000.

Mohiuddin, K.; Nizami, S.; Fitzgibbons, R. J. Jr; Watson, P.; Memon B. \& Memon, M. A. Predicting iatrogenic gall bladder perforation during laparoscopic cholecystectomy: a multivariate logistic regression analysis of risk factors. ANZ J. Surg., 76:130-2, 2006.

Morino, M.; Baracchi, F.; Miglietta, C.; Furlan, N.; Ragona, R. \& Garbarini, A. Preoperative endoscopic sphincterotomy versus laparoendoscopic rendezvous in patients with gallbladder and bile duct stones. Ann. Surg., 244:889-93, 2006.

Nande, A. G.; Shrikhande, S. V.; Rathod, V.; Adyanthaya, K. \& Shrikhande, V. N. Modified technique of gasless laparoscopic cholecystectomy in a developing country: a 5-year experience. Dig. Surg., 19:366-71, 2002.

Novitsky, Y. W.; Kercher, K. W. \& Czerniach, D. Advantages of mini-laparoscopic vs conventional laparoscopic cholecystectomy: results of a prospective randomized trial. Arch. Surg., 140:1178-83, 2005.

Nuzzo, G.; Giuliante, F. \& Giovannini, I. Bile duct injury during laparoscopic cholecystectomy: results of an Italian national survey on 56591 cholecystectomies. Arch. Surg., 140:986-992, 2005.

O.C.E.B.M. Centre for Evidence-Based Medicine. Available from: http://cebm.jr2.ox.ac.uk access on 6 June 2006.

Paganini, A. M.; Guerrieri, M. \& Sarnari, J. Thirteen years' experience with laparoscopic transcystic common bile duct exploration for stones. Effectiveness and longterm results. Surg. Endosc., 21:34-40, 2007.

Palanivelu, C.; Rajan, P. S. \& Jani, K. Laparoscopic cholecystectomy in cirrhotic patients: the role of subtotal cholecystectomy and its variants. J. Am. Coll. Surg., 203:145-51, 2006.

Pattillo, J. C.; Kusanovic, R.; Salas, P.; Reyes, J.; GarciaHuidobro, I. \& Sanhueza, M. Outpatient laparoscopic cholecystectomy. Experience in 357 patients. Rev. Med. Chil., 132:429-36, 2004.

Perez Lara, F. J.; de Luna Diaz, R.; Moreno Ruiz, J.; Suescun Garcia, R.; del Rey Moreno, A.; Hernandez Carmona, J. \& Oliva Munoz, H. Laparoscopic cholecystectomy in patients over 70 years of age: review of 176 cases. Rev. Esp. Enferm. Dig., 98:42-8, 2006.

Perez-Morales, A.; Roesch-Dietlen, F.; Diaz-Blanco, F. \& Martinez-Fernandez, S. Safety of laparoscopic cholecystectomy in complicated vesicular disease. Cir. Cir., 73:15-8, 2005.

Perissat, J.; Collet, D. R. \& Belliard, R. Gallstones: laparoscopic treatment, intracorporeal lithotripsy followed by cholecystostomy or cholecystectomy--a personal technique. Endoscopy, 21(1):373-4, 1989.

Pichon Riviere, A.; Augustovski, F.; Bardach, A.; Garcia Marti, S.; Lopez, A. \& Glujovsky, D. Laparoscopy usefulness in the management of biliary tract stones. Buenos Aires, Institute for Clinical Effectiveness and Health Policy (IECS), 2005. 
Prat, F.; Amouyal, G.; Amouyal, P.; Pelletier, G.; Fritsch, J. \& Choury, A. D. Prospective controlled study of endoscopic ultrasonography and endoscopic retrograde cholangiography in patients with suspected common bile duct lithiasis. Lancet, 347:75-9, 1996.

Regoly-Merei, J.; Ihasz, M.; Szeberin, Z.; Sandor, J. \& Mate, M. Biliary tract complications in laparoscopic cholecystectomy. A multicenter study of 148 biliary tract injuries in 26, 440 operations. Surg. Endosc., 12:294-300, 1998.

Reynolds, W. Jr. The first laparoscopic cholecystectomy. JSLS, 5:89-94, 2001.

Ros, A.; Gustafsson, L.; Krook, H.; Nordgren, C.E.; Thorell, A.; Wallin, G. \& Nilsson, E. Laparoscopic cholecystectomy versus mini-laparotomy cholecystectomy: a prospective, randomized, single-blind study. Ann. Surg., 234:741-9, 2001.

Sarmiento, J. M.; Farnell, M. B.; Nagorney, D. M.; Hodge, D. O. \& Harrington, J. R. Quality-of-life assessment of surgical reconstruction after laparoscopic cholecystectomy-induced bile duct injuries: what happens at 5 years and beyond? Arch. Surg., 139:483-8, 2004.

Schafer, M.; Schneiter, R. \& Krahenbuhl, L. Incidence and management of Mirizzi syndrome during laparoscopic cholecystectomy. Surg. Endosc., 17:1186-90, 2003.

Shekarriz, H.; Shekarriz, B. \& Kujath, P. Hydro-Jet-assisted laparoscopic cholecystectomy: a prospective randomized clinical study. Surgery, 133:635-40, 2003.

Sicklick, J. K.; Camp, M. S.; Lillemoe, K. D.; Melton, G. B.; Yeo, C. J.; Campbell, K. A; Talamini, M. A.; Pitt H. A.; Coleman, J.; Sauter, P. A.\& Cameron, J. L. Surgical management of bile duct injuries sustained during laparoscopic cholecystectomy: perioperative results in 200 patients. Ann. Surg., 241:786-92, 2005.

S.I.G.N. Scottish Intercollegiate Guidelines Network. SIGN 50: a guidelines developers' handbook. Edinburgh, SIGN, 2004.

Smith, M. 2nd; Wheeler, W. \& Ulmer, M. B. Comparison of outpatient laparoscopic cholecystectomy in a private nonteaching hospital versus a private teaching community hospital. JSLS, 1:51-3, 1997.

Sungler, P.; Heinerman, P. M. \& Steiner, H. Laparoscopic cholecystectomy and interventional endoscopy for gallstone complications during pregnancy. Surg. Endosc., 14:267-71, 2000.

Tan, J. T.; Suyapto, D. R.; Neo, E. L. \& Leong, P. S. Prospective audit of laparoscopic cholecystectomy experience at a secondary referral centre in South Australia. ANZ J. Surg., 76:335-8, 2006.

Targarona, E. M.; Marco, C.; Balague, C.; Rodriguez, J.; Cugat; E.; Hoyuela, C.; Veloso, E. \& Trias, M. How, when, and why bile duct injury occurs. A comparison between open and laparoscopic cholecystectomy. Surg. Endosc., 12:322-6, 1998.

Thornton, D. J.; Robertson, A. \& Alexander, D. J. Laparoscopic cholecystectomy without routine operative cholangiography does not result in significant problems related to retained stones. Surg. Endosc., 16:592-5, 2002.

Tranter, S. E. \& Thompson, M. H. Comparison of endoscopic sphincterotomy and laparoscopic exploration of the common bile duct. Br. J. Surg., 89:1495-504, 2002.

Trichak, S. Three-port vs standard four-port laparoscopic cholecystectomy. Surg. Endosc., 17:1434-6, 2003.

Troidl, H. Disasters of endoscopic surgery and how to avoid them: error analysis. World J. Surg., 23:846-55, 1999.

Trondsen, E.; Edwin, B.; Reiertsen, O.; Faerden, A. E.; Fagertun, H. \& Rosseland, A. R. Prediction of common bile duct stones prior to cholecystectomy. Arch. Surg., 133:162-6, 1998.

Vecchio, R.; MacFayden, B. V. \& Palazzo, F. History of laparoscopic surgery. Panminerva Med., 42:87-90, 2000.

Verma, G. R.; Lyngdoh, T. S.; Kaman, L. \& Bala, I. Placement of $0.5 \%$ bupivacaine-soaked Surgicel in the gallbladder bed is effective for pain after laparoscopic cholecystectomy. Surg. Endosc., 20:1560-4, 2006.

Vial, M.; Manterola, C.; Pineda, V. \& Losada, H. Coledocolitiasis. Elección de una terapia basada en la evidencia. Revisión sistemática de la literatura. Rev. Chil. Cir., 57:404-11, 2005.

Weber, D. M. Laparoscopic surgery: an excellent approach in elderly patients. Arch. Surg., 138:1083-8, 2003.

Wei, Q.; Wang, J. G.; Li, L. B. \& Li, J. D. Management of choledocholithiasis: comparison between laparoscopic common bile duct exploration and intraoperative 
MANTEROLA, C.; PINEDA, V.; TORT, M.; TARGARONA, E.; VILLEGAS, P. R. \& ALONSO, P. Effectiveness of laparoscopic surgery for gallstones and and common bile duct lithiasis: a systematic overview. Int. J. Morphol., 28(3):729-742, 2010.

endoscopic sphincterotomy. World J. Gastroenterol., 9:2856-8, 2003.

Weil, B. Cholelithiasis: therapeutic strategy. Report from an European concensus conference. Gastroenterol. Clin. Biol., 16:251-4, 1992.

Woods, M. S. Estimated costs of biliary tract complications in laparoscopic cholecystectomy based upon Medicare cost/charge ratios. A case-control study. Surg. Endosc., 10:1004-7, 1996.

Yano, H.; Okada, K.; Kinuta, M.; Nakano, Y.; Tono, T.; Matsui, S.; Iwazawa, T.; Kanoh, T. \& Monden, T. Efficacy of absorbable clips compared with metal clips for cystic duct ligation in laparoscopic cholecystectomy. Surg. Today, 33:18-23, 2003.

Yeh, C. N.; Jan, Y. Y.; Liu, N. J.; Yeh, T. S. \& Chen, M. F. Endo-GIA for ligation of dilated cystic duct during laparoscopic cholecystectomy: an alternative, novel, and easy method. J. Laparoendosc. Adv. Surg. Tech. A, 14:153-7, 2004.

Young-Fadok, T. M.; Smith, C. D. \& Sarr, M. G. Laparoscopic minimal-access surgery: where are we now? Where are we going? Gastroenterology, 118:S148$65,2000$.

Zacks, S. L.; Sandler, S. R.; Rutledge, R. \& Brown, S. R. Jr. A population-based cohort study comparing laparoscopic cholecystectomy and open cholecystectomy. Am. J. Gastroenterol., 97:334-40, 2002.

Zhou, H. X.; Guo, Y. H.; Yu, X. F.; Bao, S. Y.; Liu, J. L.; Zhang, Y. \& Ren, Y. G. Zeus robot-assisted laparoscopic cholecystectomy in comparison with conventional laparoscopic cholecystectomy. Hepatobiliary Pancreat. Dis. Int., 5:115-8, 2006.

\section{Correspondence to: Dr. Carlos Manterola Department of Surgery Universidad de La Frontera. Casilla 54-D, Temuco CHILE}

Phone: 56-45-325760

Fax: 56-45-325761

Email: cmantero@ufro.cl

Received: 19-03-2010

Accepted: 25-05-2010 